\title{
Cardio-respiratory studies in a patient with an absent left pulmonary artery
}

\author{
P. L. LA NDRIGAN ${ }^{1}$, I. E. PURKIS, D. E. ROY, \\ AND L. CUDKOWICZ

\begin{abstract}
From the Department of Medicine and Anaesthesia, Dalhousie University, and the Victoria General Hospital, Halifax, Nova Scotia
\end{abstract}

Congenital absence of a main pulmonary artery to one lung is a well-documented anomaly (Fraentzel, 1868 ; Miller, 1937 ; Blalock, 1948 ; Findlay and Maier, 1951; Madoff, Gaensler, and Strieder, 1952) and its association with unilateral cystic lung disease was emphasized in particular by Mannix and Haight (1955) and by Steinberg (1958). According to Madoff and others, a preponderance of congenital cardiac defects is apparent in patients with an absence of the left pulmonary artery. In their own report of a patient with a right-sided anomaly, other congenital heart defects were absent. When a lung is deprived of its main pulmonary arterial circulation, there is considerable expansion of a systemic collateral circulation (Bloomer, Harrison, Lindskog, and Liebow, 1949).

Haemoptyses, usually stemming from the expanded arterial collateral circulation (Cudkowicz, 1952), are a frequent, early, and most distressing symptom (Findlay and Maier, 1951) and pneumonectomy may be necessary. Such a decision may also be reinforced by the failure of bronchospirometry to demonstrate a significant oxygen consumption by the affected lung. Oxygen uptakes varying from 0 to $7 \%$ of the total consumption have been found under such circumstances (Madoff et al., 1952 ; Smart and Pattinson, 1956 ; Fishman, Turino, Brandfonbrener, and Himmelstein, 1958; Tabakin, Hanson, Adhikari, and Miller, 1960), suggesting little, if any, participation in gas exchange by the abnormal lung.

Fishman and his colleagues (1958) and Tabakin and others (1960), however, added to the study of the function of these lungs during bronchospirometry by the inclusion of such additional measurements as $\mathrm{CO}_{2}$ excretion and 'effective' bronchial blood flows. Here we report a patient with congenital absence of the left main pulmonary artery, whose clinical findings

${ }^{1}$ In receipt of Grant No. 9310-73 from the Defence Research Board. suggested, and routine investigations confirmed, the diagnosis. Additional information supporting this diagnosis and concerning particularly the quantity of 'effective' bronchial collateral blood flow, as well as the participation of the affected lung in overall gas exchange, was obtained during bronchospirometry.

\section{CASE REPORT}

A 44-year-old white housewife was admitted to the Victoria General Hospital, Halifax, N.S., in March 1960 because of a persistent cough and mucoid sputum. These symptoms began in 1954 and followed an upper respiratory infection, an incident which previously had left no sequelae. In 1957 she contracted a left-sided pneumonia and for some time afterwards expectorated purulent green sputum which on only one occasion became blood-stained. When the purulent sputum subsided, the cough remained. She denied other symptoms and seemed unaware of breathlessness.

The clinical findings were confined to the chest, which disclosed a decrease in expansion, impairment in percussion note, and absence of tactile fremitus and vocal resonance in the area of the left lower lobe. Medium and low-pitched expiratory wheezes were audible in the same territory. Clubbing of the fingers was absent, the colour of the mucous membranes was normal, and the neck veins showed no engorgement. The apex beat was not displaced, and the heart sounds were normal. A medium-pitched midsystolic murmur of $1 / 6$ intensity was present along the left sternal border, loudest in the second left intercostal space, as well as a high-pitched early diastolic murmur of similar intensity and distribution. The peripheral pulses were equal, the rhythm regular, and the blood pressure was $120 / 75 \mathrm{~mm}$. $\mathrm{Hg}$.

SPECIAL INVESTIGATIONS The haemoglobin was 14.5 g. $/ 100$ ml. ; P.C.V., 48\% ; W.B.C., 9,900/c.mm. with a normal differential count. Erythrocyte sedimentation rate was $26 \mathrm{~mm}$. in one hour. Serology was negative. Plasma proteins: total, $6.5 \mathrm{~g} . / 100 \mathrm{ml}$.; albumin, 4.2 g. $/ 100 \mathrm{ml}$; globulin, 2.3 g. $/ 100 \mathrm{ml}$. Repeated sputum cultures demonstrated a normal flora and cultures for tubercle bacilli were negative. 


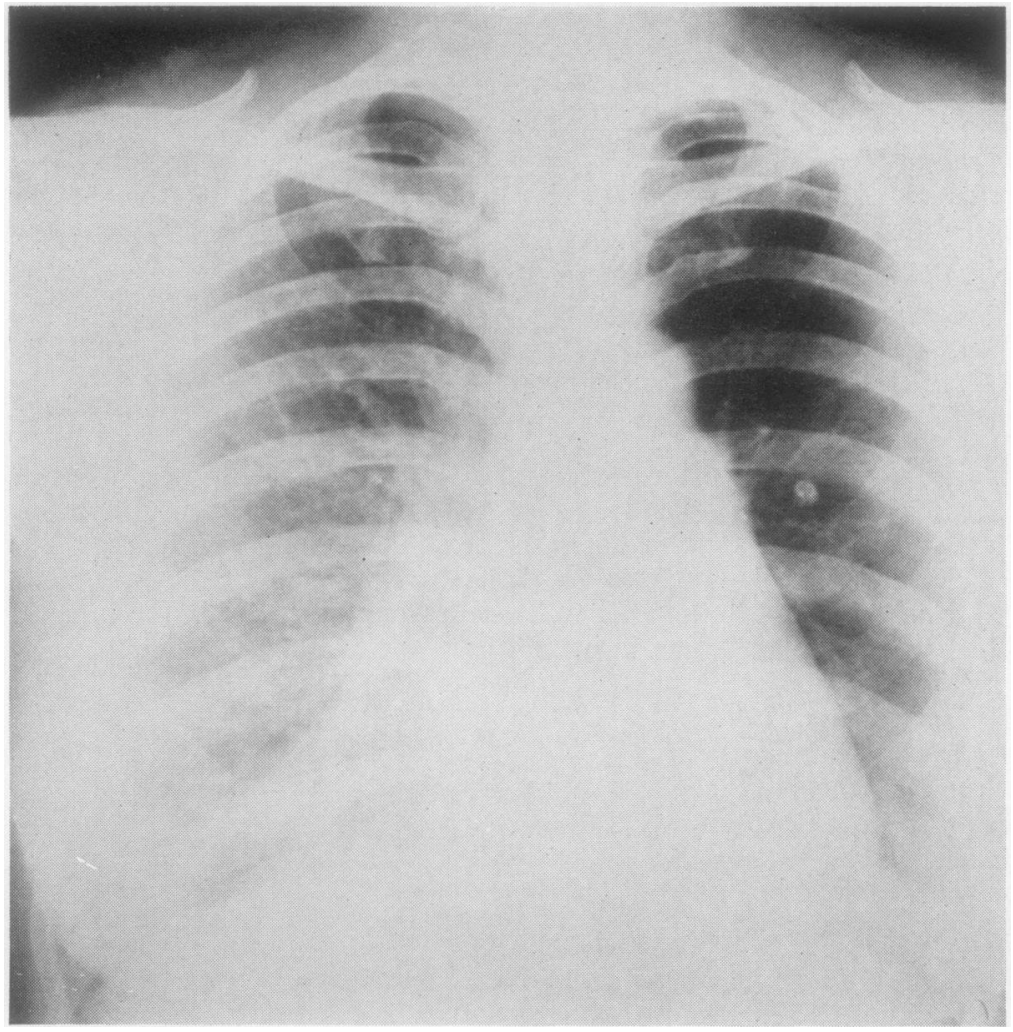

FIG. 1. Radiograph shows trans $\overparen{\overparen{D}}$ lucency of left lung field.

FIG. 2. Left bronchogram shows ectasia of left lower lobe bronchi and small cysts in communications with abnormal bronchi.

FIG. 1

Electrocardiograms revealed a variable atrial pacemaker.

Radiographs of the chest showed an increase in translucency of the left lung fields, plethora of the right lung, and a normal cardiac silhouette (Fig. 1). Tomography of the left lung failed to depict a left pulmonary artery shadow. Bronchography revealed extensive bronchiectasis and some cystic changes in the left lung which communicated with the bronchi (Fig. 2).

CARDIAC CATHETERIZATION The catheter could not be passed into the left main pulmonary artery. A dye dilution curve recorded from a femoral artery, after delivery of the bolus into the main pulmonary artery, revealed a normal contour. An angiocardiogram from the right ventricle showed the absence of the left main pulmonary artery, as well as anomalous primary branching of the right main pulmonary artery (Fig. 3).

RESPIRATORY FUNCTION STUDIES Table I summarizes the respiratory function tests, which show moderately severe restrictive lung disease, as well as enlargement of physiological dead space and an abnormally high alveolar-arterial $\mathbf{P C O}_{2}$ gradient. The alveolar ventilation was normal, and the carbon monoxide diffusing capacity was reduced by more than 50 per cent.






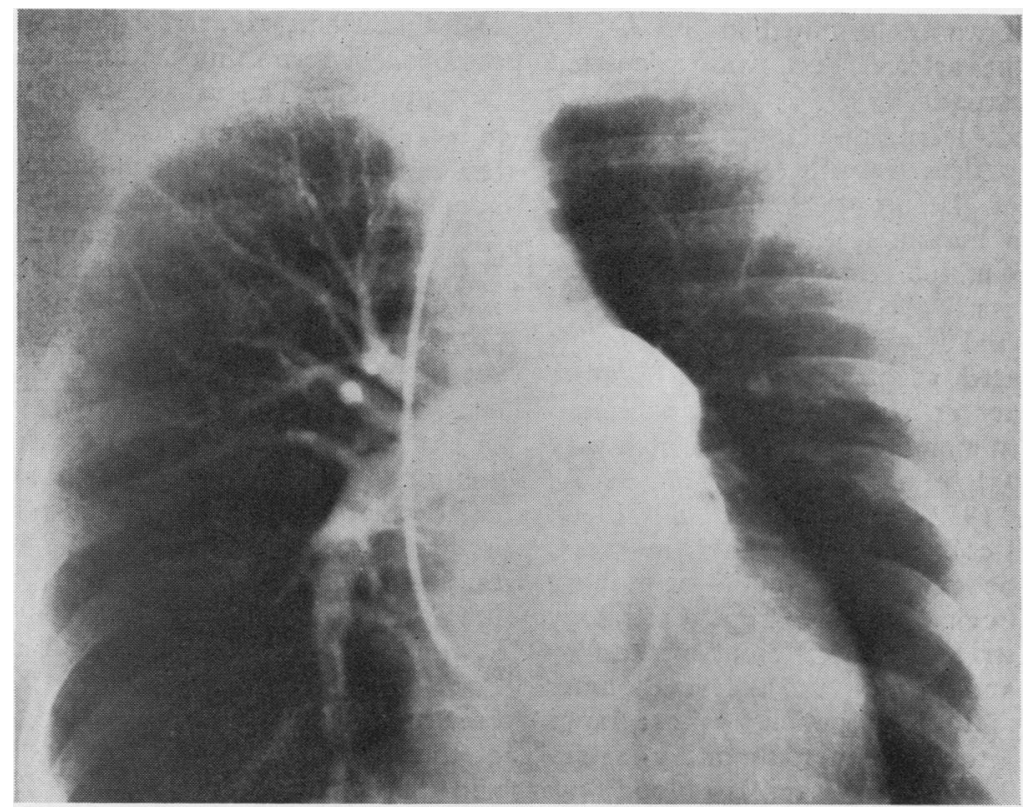

FIG. 3. Pulmonary angiogram shows an absence of the left pulmonary artery and two large abnormal divisions reaching the right upper lobe.

TABLE I

PULMONARY FUNCTION STUDIES

\begin{tabular}{|c|c|c|}
\hline & $\begin{array}{l}\text { Actual } \\
\text { Values }\end{array}$ & $\begin{array}{l}\text { Normal } \\
\text { Standards } \\
(\% \text { of Normal) }\end{array}$ \\
\hline 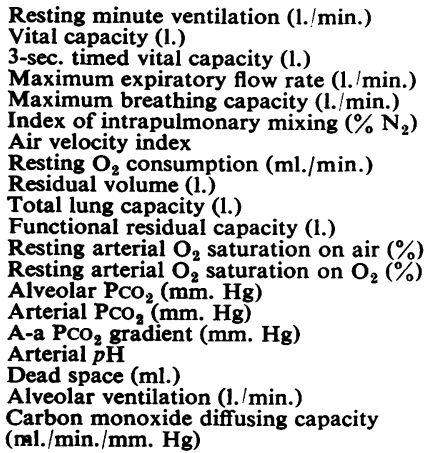 & $\begin{array}{c}7 \cdot 16 \\
2 \cdot 27 \\
2 \cdot 0 \\
290 \\
97 \cdot 5 \\
0 \cdot 8 \\
1 \cdot 1 \\
195 \cdot 0 \\
1 \cdot 29 \\
3 \cdot 54 \\
1 \cdot 5 \\
95 \\
100 \\
30 \\
40 \\
10 \\
7 \cdot 36 \\
280 \\
4 \cdot 76\end{array}$ & $\begin{array}{l}82.4 \\
88 \cdot 4 \\
81 \cdot 7 \\
91 \cdot 4 \\
2 \cdot 0 \\
0.8-1 \cdot 1 \\
\\
4 \cdot 21 .\end{array}$ \\
\hline
\end{tabular}

\section{BRONCHOSPIROMETRY}

Bronchospirometry was used to measure the following: (1) minute ventilation and $\mathrm{CO}_{2}$ elimination from each lung while both lungs respired ambient air ; (2) oxygen consumption and minute ventilation of each lung while both lungs respired oxygen ; $(3)$ oxygen consumption by the left lung on oxygen, while the normal right lung respired air; and (4) oxygen consumption by the left lung on oxygen, while the normal right lung respired a $10 \%$ oxygen in nitrogen mixture.

METHOD After topical anaesthesia and without premedication a 37 Carlens' catheter was placed so that its distal lumen entered the left main bronchus. Its position was checked by fluoroscopy. The absence of gross leaks was established once air could no longer be displaced from one spirometer to the other. After the cuffs had been inflated the reduction in the left respiratory movements, already noted clinically, became immediately apparent in the left spirogram.

For measurements of minute ventilation, alveolar and dead space ventilations, and $\mathrm{CO}_{2}$ output during ambient air breathing, expired air was collected for three minutes in two anaesthetic bags interposed between the expiratory circuits and the spirometers by two three-way valves.

Arterial blood was collected through a Cournand needle placed in a brachial artery during the third minute of the first three procedures and in the first minute of the fourth study.

The oxygen content and capacity of whole blood were determined by the Van-Slyke-Neill manometric apparatus. The gas volumes of the bags were measured in a Tissot gasometer and the $\mathrm{CO}_{2}$ content analysed in duplicate in a modified Haldane gas analyser (Campbell, 1960). Whole 
arterial blood $p \mathrm{H}$ was determined in the Astrup apparatus, and the arterial $\mathrm{PCO}_{2}$ was calculated by the Astrup technique.

For the second, third, and fourth study the respective gas mixtures were introduced into the 9-litre spirometers. Before the bilateral oxygen consumption was measured both lungs respired oxygen for three minutes before being switched into the spirometers.

Effective bronchial arterial blood flow to the left lung was calculated according to the Bloomer technique (Bloomer et al., 1949), and adaptation of this technique in man gives estimates which vary from 0.86 to $1.91 . / \mathrm{min}$. (Madoff et al., 1952; Fishman et al., 1958; Tabakin et al., 1960). Bronchial arterial collateral blood flows in excess of this have to be expected in main pulmonary artery atresia associated with Fallot's tetralogy and were demonstrated by a different method by Bing, Vandam, and Gray (1947). The Bloomer technique assumes that, in patients whose lungs are deprived of their main pulmonary artery circulation, all left pulmonary capillary blood flow is systemic in source and has a precapillary $\mathrm{O}_{2}$ content equivalent to that of brachial arterial blood while both lungs respire air. This oxygen content is expressed as $\mathrm{CaO}_{2}$. On switching the left lung to oxygen the left alveolar $\mathrm{Po}_{2}$ rises rapidly and a new left alveolar-capillary $\mathrm{Po}_{2}$ gradient is established, permitting $\mathrm{O}_{2}$ diffusion to occur at that new gradient. The uptake of oxygen by the left lung is measured and is expressed as $\dot{V}_{O_{2}} \mathrm{LBA}$. It is assumed that the left pulmonary venous blood is now fully saturated and that its content is equal to that of the arterial $\mathrm{O}_{2}$ capacity. By applying Fick's principle, the collateral bronchial blood flow QBA to the left lung can be calculated as follows :

$$
\dot{\mathrm{Q}} \dot{\mathrm{BA}}=\frac{\dot{\mathrm{V}}_{2} \mathrm{LBA}}{\text { arterial } \mathrm{O}_{2} \text { capacity }-\mathrm{CaO}_{2}} \times 100
$$

RESUlts Table II shows that the left lung participated in $10.1 \%$ of a total minute ventilation of $8.25 \mathrm{l} . / \mathrm{min}$. Similarly, $8.45 \%$ of a total $\mathrm{CO}_{2}$ output of $284 \mathrm{ml} . / \mathrm{min}$. was derived from the left lung. The overall alveolar ventilation of 5.66 $1 . / \mathrm{min}$. was normal and maintained the arterial $\mathrm{PCO}_{2}$ at $40 \mathrm{~mm}$. Hg. During bilateral oxygen breathing (Table III), the left lung took up $11.9 \%$ of the total oxygen consumption of $305 \mathrm{ml} . / \mathrm{min}$. and participated in $8.5 \%$ of the total minute ventilation of $7 \cdot 231 . / \mathrm{min}$. The arterial oxygen saturation, which was $93 \%$, rose to $100 \%$ during bilateral oxygen breathing. With the left lung on oxygen alone, the arterial oxygen saturation dropped to $97 \%$, but an increase in oxygen

TABLE II

BRONCHOSPIROMETRIC MEASUREMENTS ON AMBIENT AIR

\begin{tabular}{|c|c|c|c|c|c|c|}
\hline & $\begin{array}{l}\text { Right } \\
\text { Lung }\end{array}$ & $\begin{array}{l}\% \text { of } \\
\text { Total }\end{array}$ & $\begin{array}{l}\text { Left } \\
\text { Lung }\end{array}$ & $\begin{array}{l}\% \text { of } \\
\text { Total }\end{array}$ & Total & $\begin{array}{l}\text { Arterial Blood } \\
\text { Analyses }\end{array}$ \\
\hline Minute ventilation ( $1 . \min )$. & $7 \cdot 42$ & 89.9 & 0.83 & $10 \cdot 1$ & $8 \cdot 25$ & $\begin{array}{l}\mathrm{Hb} 15.5 \mathrm{~g} .100 \mathrm{ml} . \\
\mathrm{O}_{2} \text { content } 19.5 \text { vol. } \%\end{array}$ \\
\hline $\begin{array}{l}\text { Rate of respiration } \\
\mathrm{CO}_{2} \text { output (ml.'min.) }\end{array}$ & $\begin{array}{r}11 \\
260\end{array}$ & $91 \cdot 55$ & $\begin{array}{l}11 \\
24\end{array}$ & $8 \cdot 45$ & 284 & $\mathrm{O}_{2}$ capacity 20.49 vol. $\%$ \\
\hline Alveolar ventilation ( $1 . \mathrm{min}$.) & & & & & $5 \cdot 66$ & $\begin{array}{l}\mathrm{PCO}_{2} 40 \mathrm{~mm} . \mathrm{Hg} \\
p \mathrm{H} \cdot 38\end{array}$ \\
\hline $\begin{array}{l}\text { Dead space ventilation ( } 1 . / \mathrm{min} .) \\
\text { Physiological dead space (ml.) }\end{array}$ & & & & & $234^{2 \cdot 59}$ & \\
\hline
\end{tabular}

TABLE III

BRONCHOSPIROMETRIC MEASUREMENTS WITH BOTH LUNGS ON OXYGEN

\begin{tabular}{|c|c|c|c|c|c|c|}
\hline & $\begin{array}{l}\text { Right } \\
\text { Lung }\end{array}$ & $\begin{array}{l}\% \text { of } \\
\text { Total }\end{array}$ & $\begin{array}{l}\text { Left } \\
\text { Lung }\end{array}$ & $\begin{array}{l}\% \text { of } \\
\text { Total }\end{array}$ & Total & $\begin{array}{l}\text { Arterial Blood } \\
\text { Analyses }\end{array}$ \\
\hline $\begin{array}{l}\mathrm{O}_{2} \text { consumption }(\mathrm{ml} \text {. } \mathrm{min} .) \\
\text { Minute ventilation }(\mathrm{l} \text {.' } \mathrm{min} .) \\
\text { Ventilatory equivalent for } \mathrm{O}_{2}\left(1 . \text { ' }^{\mathrm{min}} \text {.) }\right.\end{array}$ & $\begin{array}{r}269 \\
6 \cdot 58 \\
2 \cdot 45\end{array}$ & $\begin{array}{l}88 \cdot 1 \\
91 \cdot 5\end{array}$ & $\begin{array}{r}36 \cdot 0 \\
0.65 \\
1 \cdot 79\end{array}$ & $\begin{array}{r}11 \cdot 9 \\
8 \cdot 5\end{array}$ & $\begin{array}{l}305 \\
7 \cdot 23\end{array}$ & $\begin{array}{l}\mathrm{O}_{2} \text { content } 20.39 \text { vol. } \% \\
\mathrm{O}_{2} \text { capacity } 20.30 \text { vol. } \% \\
\mathrm{O}_{2} \text { saturation } 100 \% \\
\mathrm{PCO}_{2} 34.5 \mathrm{~mm} . \mathrm{Hg}\end{array}$ \\
\hline
\end{tabular}

TABLE IV

BRONCHOSPIROMETRIC MEASUREMENTS WITH RIGHT LUNG ON AMBIENT AIR AND LEFT LUNG ON OXYGEN

\begin{tabular}{|c|c|c|c|c|c|c|}
\hline & $\begin{array}{l}\text { Right } \\
\text { Lung }\end{array}$ & $\begin{array}{l}\% \text { of } \\
\text { Total }\end{array}$ & $\begin{array}{l}\text { Left } \\
\text { Lung }\end{array}$ & $\begin{array}{l}\% \text { of } \\
\text { Total }\end{array}$ & Total & $\begin{array}{l}\text { Arterial Blood } \\
\text { Analyses }\end{array}$ \\
\hline $\begin{array}{l}\mathrm{O}_{2} \text { consumption }(\mathrm{ml} / \mathrm{min} .) \\
\text { Minute ventilation }(1 . \min .)\end{array}$ & $6 \cdot 64$ & 89.0 & $\begin{array}{l}45 \cdot 0 \\
0 \cdot 822\end{array}$ & $11 \cdot 0$ & $7 \cdot 46$ & $\begin{array}{l}\mathrm{O}_{2} \text { content } 19.9 \mathrm{vol} \% \\
\mathrm{O}_{2} \text { saturation } 97.0 \% \\
\mathrm{PCO}_{2} 35.5 \mathrm{~mm} . \mathrm{Hg}\end{array}$ \\
\hline
\end{tabular}


TABLE V

BRONCHOSPIROMETRIC MEASUREMENTS WITH RIGHT LUNG ON $10 \%$ OXYGEN IN NITROGEN AND LEFT LUNG ON OXYGEN

\begin{tabular}{|c|c|c|c|c|c|c|}
\hline & $\begin{array}{l}\text { Right } \\
\text { Lung }\end{array}$ & $\begin{array}{l}\% \text { of } \\
\text { Total }\end{array}$ & $\begin{array}{l}\text { Left } \\
\text { Lung }\end{array}$ & \% of & Total & $\begin{array}{l}\text { Arterial Blood } \\
\text { Analyses }\end{array}$ \\
\hline $\begin{array}{l}\mathbf{O}_{2} \text { consumption }(\mathrm{ml} . / \mathrm{min} .) \\
\text { Minute ventilation }(1 . / \mathrm{min} .)\end{array}$ & 12.04 & 90.8 & $\begin{array}{r}85 \cdot 0 \\
1 \cdot 23\end{array}$ & $9 \cdot 2$ & $13 \cdot 27$ & $\begin{array}{l}\mathrm{O}_{2} \text { content } 10.24 \text { vol. } \% \\
\mathrm{O}_{2} \text { capacity } 20.59 \text { vol..\% } \\
\mathrm{O}_{2} \text { saturation } 49.2 \% \\
\mathrm{PCO}_{2} 34.5 \mathrm{~mm} . \mathrm{Hg}\end{array}$ \\
\hline
\end{tabular}

consumption from 36 to $45 \mathrm{ml} . / \mathrm{min}$. occurred (Table IV) with a slight rise in minute ventilation. When the right lung was placed on a $10 \%$ oxygen in nitrogen mixture the arterial oxygen saturation dropped to $49.2 \%$ in spite of an almost $100 \%$ increase in the oxygen consumption of the left lung, which continued to respire pure oxygen. The systemic arterial hypoxaemia raised the total minute ventilation to $13.271 . / \mathrm{min}$., but the restrictive disease of the left lung provided that lung with only $9 \cdot 2 \%$ of the total minute ventilation (Table V). The effective left bronchial arterial blood flow calculated from procedures 2 and 3 was:

$$
\begin{aligned}
\dot{Q} \mathbf{L} B A & =\frac{\dot{\mathrm{VO}_{2} \mathrm{LBA}}}{\text { arterial } \mathrm{O}_{2} \text { capacity }-\mathrm{CaO}_{2}} \\
& =\frac{45}{20.39-19.5} \times 100=506 \mathrm{ml} . / \mathrm{min}
\end{aligned}
$$

\section{DISCUSSION}

The associated bronchiectatic and cystic lesions of the left lung of this patient appear to have restricted its movements so that its participation in total minute ventilation was only 10 to 11 per cent. The overall alveolar ventilation in the presence of the enlarged physiological dead space remained adequate, as shown by the normal arterial $\mathrm{PCO}_{2}$ levels. Because there were grossly restricted movements of the left lung, participation in gas exchange was equally impaired and only $8.5 \%$ of the total $\mathrm{CO}_{2}$ elimination during ambient air breathing stemmed from the left lung and its systemic blood supply. Nevertheless, the oxygen consumption increased by raising the left alveolarcapillary $\mathrm{Po}_{2}$ gradient or during deliberate reduction of that of the right lung. The limit in participation of gas exchange was imposed on the left lung of this patient by the reduced diffusing capacity and the relatively low effective bronchial arterial blood flow of $0.51 . /$ minute. In the two studies reported by Tabakin and others (1960), the bronchial arterial blood flows were 1.83 and $1.81 \mathrm{1} / \mathrm{min}$. respectively. It is also of interest that, in the two patients studied by these authors, the left lungs contributed 52 and $35 \%$ respectively to the total ventilation, whereas the oxygen consumptions of the anomalous sides were 7 and $5 \%$, respectively. The corresponding $\mathrm{CO}_{2}$ excretions were 37 and $26 \%$ of the total, respectively, with a normal diffusing capacity, measured in their second patient only, of $24 \mathrm{ml} . / \mathrm{min} . / \mathrm{mm}$. Hg. These observations would thus be in keeping with an almost normal participation in alveolar ventilation and a slightly lowered systemic arterial-left alveolar $\mathrm{PCO}_{2}$ gradient.

A lung deprived of a main pulmonary artery and endowed with a large bronchial collateral circulation continues to possess useful respiratory function. Elimination of $\mathrm{CO}_{2}$ from such a lung renders it active in effective alveolar ventilation. The $\mathrm{CO}_{2}$ component derived from this lung has the effect of diminishing physiological dead space and thereby reduces the obligatory minute ventilation. A low oxygen consumption alone by the anomalous lung, while oxygen is respired bilaterally during bronchospirometry, is unlikely to provide full information concerning total respiratory function of that lung, particularly as the oxygen consumption of that lung clearly can be increased during any deliberate reduction in systemic blood $\mathrm{Po}_{2}$ tension. This manoeuvre in conjunction with separate $\mathrm{CO}_{2}$ measurements seems necessary in any assessment concerning its participation in gas exchange, particularly if a pneumonectomy is contemplated as a respite from haemoptyses.

\section{SUMMARY}

In a patient with an absent left pulmonary artery and associated left-sided bronchiectasis and cystic lung disease, the clinical diagnosis was established by radiography and a right ventricular angiogram. Bronchospirometry revealed that the left lung participated in $10.1 \%$ of the total minute ventilation, eliminated $8.45 \%$ of the total $\mathrm{CO}_{2}$ excretion, and shared in $11.9 \%$ of the total oxygen consumption. The left lung oxygen consumption of 36 $\mathrm{ml} . / \mathrm{min}$. increased to $45 \mathrm{ml} . / \mathrm{min}$. while respiring the right lung on air alone and reached $85 \mathrm{ml} . / \mathrm{min}$. if a $10 \%$ oxygen mixture in $\mathrm{N}_{2}$ was respired to the normal lung. The effective collateral arterial blood supply to the left lung was calculated at 
0.506 millilitre/minute. The significance of these findings is discussed.

We wish to thank Mr. L. Diamond, Department of Medical Photography, Dalhousie University, for the reproduction of the radiographs.

\section{REFERENCES}

Bing, R. J., Vandam, L. D., and Gray, F. D., Jr. (1947). Bull. Johns Hopk. Hosp., 80, 107, 121.

Blalock, A. (1948). Surg. Gynec. Obstet., 87, 385.

Bloomer, W. E., Harrison, W., Lindskog, G. E., and Liebow, A. A. (1949). Amer. J. Physiol., 157, 317.
Campbell, E. J. M. (1960). Brit. med. J., 1, 457

Cudkowicz, L. (1952). Thorax, 7, 270.

Findlay, C. W., Jr., and Maier, H. C. (1951). Surgery, 29, 604.

Fishman, A. P., Turino, G. M., Brandfonbrener, M., and Himmelstein, A. (1958). J. cli i. Invest., 37, 1071.

Fraentzel, O. (1868). Virchows Arch. path. Anat., 43, 420.

Madoff, I. M., Gaensler, E. A., and Strieder, J. W. (1952). New Engl. ڤి J. Med., 247, 149.

Mannix, E. P., Jr., and Haight, C. (1955). Medicine (Baltimore), $\overrightarrow{0}$ 34, 193.

Miller, J. F. (1937). Amer. J. Dis. Child., 53, 1268.

Smart, J., and Pattinson, J. N. (1956). Brit. med. J., 1, 491.

Steinberg, I. (1958). Amer. J. Med., 24, 559.

Tabakin, B. S., Hanson, H. S., Adhikari, P. K., and Miller, D. B. (1960). Circulation, 22, 1107. 